\title{
A proposed unified terminology of species traits in stream ecology
}

\author{
Dénes Schmera ${ }^{1,2,7}$, János Podani ${ }^{3,4,8}$, Jani Heino ${ }^{5,9}$, Tibor Erős ${ }^{2,10}$, and N. LeRoy Poff ${ }^{6,11}$ \\ ${ }^{1}$ Section of Conservation Biology, University of Basel, St Johanns-Vorstadt 10, CH-4056 Basel, Switzerland \\ ${ }^{2}$ Balaton Limnological Institute, Centre for Ecological Research, Hungarian Academy of Sciences, Klebelsberg K. u. 3, H-8234 \\ Tihany, Hungary \\ ${ }^{3}$ Department of Plant Systematics, Ecology and Theoretical Biology, Institute of Biology, L. Eötvös University, Pázmány P. s. 1/C, \\ H-1117 Budapest, Hungary \\ ${ }^{4}$ Ecology Research Group of the Hungarian Academy of Sciences, Pázmány P. s. 1/C, H-1117 Budapest, Hungary \\ ${ }^{5}$ Biodiversity, Natural Environment Centre, Finnish Environment Institute, P.O. Box 413, FI-90014 Oulu, Finland \\ ${ }^{6}$ Department of Biology and Graduate Degree Program in Ecology, Colorado State University, Forth Collins, Colorado 80523 USA
}

\begin{abstract}
Traits-based community analyses are receiving increasing attention. However, consistent interpretation of empirical results and ecological understanding in stream ecology are limited by ambiguous terminology. Furthermore, the measurement scales used to analyze trait data, especially ordinal-scale data, are often inappropriately applied. We identify and discuss these shortcomings and offer a solution for an operative and algebraically correct treatment of traits and a unified nomenclature that facilitates direct comparison among traits-based studies. A unified terminology allows for logical translation among existing, alternative trait nomenclatures and should facilitate communication of research findings among stream ecologists and more directly connect stream traits-based research with general ecology.
\end{abstract}

Key words: species traits, stream ecology, macroinvertebrates, measurement scale, terminology

Understanding and predicting the structure of biological communities are among the main goals of ecology. Early efforts provided robust explanation for variation in community structure based on the taxonomic identity of organisms. Recently, however, the importance of traitsbased approaches, which rely on biological attributes (e.g., feeding, life-history) has been re-emphasized because these approaches hold the promise to refine our mechanistic understanding of biological communities in a taxonindependent manner (McGill et al. 2006, Verberk et al. 2013). Traits-based data are easily compared across ecosystems and may facilitate establishing stronger links between community and ecosystem ecology (Webb et al. 2010).

Traits-based approaches have long been used in freshwater ecology to relate species performance to community patterns along environmental gradients (Cummins 1973, Ricci 1991, Winemiller 1991, Vaughn et al. 1993). The adaptation of the habitat templet theory to river systems (Poff and Ward 1990, Townsend and Hildrew 1994) and the link of landscape filters to the traits of organisms (Poff 1997) furthered the conceptual foundations of our present understanding of traits-based community organization in running waters. The term 'species trait' is clearly derived from evolutionary biology and ecology. However, characterizing individual species or communities of species in terms of their traits and analyzing them across environmental gradients require careful adherence to the underlying mathematical or statistical structure implicit in these relationships (Webb et al. 2010). Thus, a clear need exists for drawing inferences using statistical and mathematical approaches.

E-mail addresses: ${ }^{7}$ denes.schmera@unibas.ch; ${ }^{8}$ podani@ludens.elte.hu; ${ }^{9}$ jani.heino@environment.fi; ${ }^{10}$ eros.tibor@okologia.mta.hu; ${ }^{11}$ poff@lamar.colostate.edu

"This section of the journal is for the expression of new ideas, points of view, and comments on topics of interest to aquatic scientists. The Editorial Board invites new and original papers as well as comments on items already published in Freshwater Science. Format and style may be less formal than conventional research papers; massive data sets are not appropriate. Speculation is welcome if it is likely to stimulate worthwhile discussion. Alternative points of view should be instructive rather than merely contradictory or argumentative. All submissions will receive the usual reviews and editorial assessments.

DOI: 10.1086/681623. Received 6 February 2014; Accepted 7 January 2015; Published online 1 April 2015.

Freshwater Science. 2015. 34(3):823-830. ๑ 2015 by The Society for Freshwater Science. 
In recent reviews of the literature dealing with patterns of species traits in running waters (Heino et al. 2013, Schmera et al. 2014), we found that the terminology of traits is inconsistent, and data expressing trait variables are frequently handled in a mathematically incorrect way. Here, we identify these shortcomings and suggest a solution for an operative and algebraically meaningful treatment of traits. We emphasize that consistent terminology would help us to improve comparisons among traits-based studies across many subdisciplines of ecology and to generalize results obtained for different taxa or habitat types.

\section{MATHEMATICAL TERMS AND MEASUREMENT SCALES IN STREAM ECOLOGY}

In biology, any character (e.g., color) that may differ over entities (e.g., species) is termed a variable, variate (Zar 1999, p. 2), or descriptor (Legendre and Legendre 2012, p. 28). A fundamental property of every variable (or descriptor) is that each biological object is characterized by 1 element (e.g., brown) of a set of distinguishable states of that variable (Legendre and Legendre 2012). The quality of information about biological objects determines the measurement scale of the variables, and the measurement scale constrains the mathematical methods applicable to processing and evaluating the data. A variable may be expressed on different measurement scales-nominal, ordinal, interval, and ratioeach with specific mathematical properties (Table 1).

In stream ecology, the most frequently used measurement scales are nominal, ordinal, and ratio. These scales are applied to so-called states of some traits, such as adult life span, adult dispersal ability, and more (see Poff et al. 2006). Here, we discuss the important mathematical properties of using these measurement scales to describe states. Below, we apply these mathematical criteria to a more formal definition of state in a proposed unified nomenclature.

On the nominal scale, states are distinguishable but cannot be ordered (e.g., locomotion habits of stream macroinvertebrates: burrow, climb, sprawl, cling, swim, and skate; see Poff et al. 2006). The only statement we can make on 2 states is whether they agree $(=)$ or not $(\neq)$ (Anderberg 1973).
In case of ordinal-scale variables, states or scores can be ordered (e.g., swimming ability of stream macroinvertebrates: none, weak, and strong; see Poff et al. 2006), so that operations < and > also are meaningful. However, on this measurement scale, differences between states are not interpreted: the difference between none and weak cannot be compared to the difference between weak and strong. Thus, we cannot calculate the mean and the ratio of these values, even if they are coded by numerals, such as 0,1 , and 2 , for the purpose of data processing. The ordinal scale is probably the most difficult to evaluate. Statistical methods do exist to evaluate ordinal-scale variables, but the ordinal scale frequently is simplified to the nominal scale (so that we lose the sequential information) or is expanded to interval scale (for problems, see below).

The interval scale allows the operation of subtraction $(-)$, so that sums, means, and variances are meaningful. This measurement scale has no mathematical 0 point (e.g., when temperature is measured in ${ }^{\circ} \mathrm{C}$ or ${ }^{\circ} \mathrm{F}$ ), so ratios do not make sense. However, the Kelvin scale of temperature allows calculation of temperature ratios because the lowest possible temperature is the mathematical 0 point. This brings us to the ratio scale, for which the operation of division is also meaningful: a 20-cm-long fish is twice as long as a 10-cm-long fish. This property exists because the 0 point disallows measuring negative values. Although not stated explicitly, fuzzy coding (Chevenet et al. 1994) uses the ratio (rather than the ordinal) scale implicitly because both the developers of the coding system (Chevenet et al. 1994, p. 297) and the first users in stream ecology (Usseglio-Polatera et al. 2000, p. 180) clearly stated that scores are to be converted into \%/trait (Table 2).

Variables quantified on the same mathematical scale may have different names. For instance, nonquantitative variables that must be expressed quantitatively (such as brown) are often called attributes, categorical variables, or nominal variables (Sokal and Rohlf 1995, p. 12). Furthermore, variables also can be categorized as continuous (infinite number of states; e.g., the length of a fish is $12.5 \mathrm{~cm}$ ), discrete (countable number of states; e.g., the color of an individual is yellow, brown, or black), or binary (only 2 states; e.g., yes or no), reflecting the number of states the variable can take

Table 1. Relationships between measurement scales and variables.

\begin{tabular}{|c|c|c|c|c|}
\hline Measurement scale $^{1}$ & Name of the variable ${ }^{2}$ & $\begin{array}{l}\text { Special name of a } \\
\text { particular state }\end{array}$ & Example of state & Valid operations \\
\hline Nominal & $\begin{array}{l}\text { Attribute or categorical } \\
\text { variable or nominal variable }\end{array}$ & State & $\begin{array}{l}\text { Yes/no } \\
\text { Yellow/brown/black }\end{array}$ & $=, \neq$ \\
\hline Ordinal & Ranked variable & Rank & Low, high & $=, \neq,<,>$ \\
\hline Interval & Measurement variable & Value & $10^{\circ} \mathrm{C}$ & $=, \neq,<,>,+,-$ \\
\hline Ratio & Measurement variable & Value & $12.5 \mathrm{~cm}$ & $=, \neq,<,>,+,-, /, \times$ \\
\hline
\end{tabular}

${ }^{1}$ Following Anderberg (1973)

${ }^{2}$ Following Sokal and Rohlf (1995) 
Table 2. Examples of the inconsistent use of traits terminology in stream ecology. Terms are compared to standard statistical meanings for 'variable' and 'state' (Zar 1999, Legendre and Legendre 2012) and proposed new term 'grouping feature' (see text). \%/trait = percentage of organisms with the trait.

\begin{tabular}{cclll}
\hline Example & Grouping feature & \multicolumn{1}{c}{ Variable } & State & \multicolumn{1}{c}{ Reference } \\
\hline 1 & Trait & Modality/category & Score & $\begin{array}{c}\text { Statzner et al. 1994 and refs therein, } \\
\text { Statzner et al. 1997, Usseglio-Polatera et al. } \\
\text { 2000, Bêche and Resh 2007 } \\
\text { Dolédec et al. 1999, Charvet et al. 2000, } \\
\text { Dolédec et al. 2000, Gayraud et al. 2003, } \\
2\end{array}$ \\
& Trait & Category & Score & Bady et al. 2005 \\
& & & Category/\%trait & Lamouroux et al. 2002 \\
3 & - & Trait & Value & Haybach et al. 2004 \\
4 & Category & Trait & State & Poff et al. 2006, Vieira et al. 2006 \\
5 & - & Trait & Value & Blanck and Lamouroux 2007, Schmera et al. 2009 \\
6 & - & Trait &
\end{tabular}

(Table 1). Several combinations of the measurement scale and the categories of variables based on the number of states (binary, discrete, and continuous) exist and have been discussed in detail elsewhere (Anderberg 1973). Here, we focus on specific combinations that are relevant to traitsbased analyses.

\section{TERMINOLOGICAL CONFUSION}

A trait is "a well-defined, measurable property of organisms, usually measured at the individual level and used comparatively across species" (McGill et al. 2006, p. 178). Examples of traits include morphological, physiological, or phenological features. It follows that a trait should be regarded as a variable (e.g., color) that is characterized by a state of membership or affinity (e.g., brown), which may be binary $(0 / 1)$ or continuous $(0-100 \%)$. At the species level, the state of membership can be ascribed to individuals, e.g., individuals can be brown (1) or not (0), or some fraction of individuals are brown (e.g., 30\%) and the remainder (70\%) not. Within an individual, affinities for different membership states may vary as well. For example, an individual macroinvertebrate may be coded as a predator (1) or not (0), or it shows affinity for the collector-gatherer trait $40 \%$ of the time (e.g., early instars) and then switches to some other feeding style, such as the predator trait for the remaining $60 \%$ of its life.

Traits are often grouped according to similarity of function (e.g., style of food acquisition, such as shredder, predator, scraper, etc.). We argue that such joint characterization is biologically meaningful and propose some standard terminology. We suggest using the term grouping feature for describing some general property of species (e.g., feeding style) that comprise a group of related traits (e.g., predator, shredder, etc.) that vary among species or among individuals within a species. Thus, each grouping feature is composed of a trait group, or a set of related traits. Further, for each trait (e.g., shredder), a membership state re- flects either a binary classification $(0 / 1)$ or a continuous or fuzzy classification (0-100\%). This system can be applied at the individual and species level, depending on the context, and we propose it in an effort to eliminate some previous confusion in the past literature.

As an example from the more general ecological literature, Violle et al. (2007) referred to the 'state' of a trait as either a value (if the trait is expressed on the ratio or interval measurement scale; see Table 1 for definitions) or a modality (if the trait is measured on the nominal scale). They also proposed (following the nomenclature of Lavorel et al. 1997) that a given value or modality should more generally be called an attribute. However, in standard statistical nomenclature an attribute is technically a variable and, thus, more appropriately applied to a trait rather than to a membership state. Therefore, we do not follow that proposal here.

In the 1990s, a large research team studying the Upper Rhône River (hereafter referred to as the Rhône group; see Chevenet et al. 1994, Dolédec and Chessel 1994, Statzner et al. 1994) pioneered the use of species traits (or, more specifically, taxon traits) to characterize entire aquatic communities. They defined species traits as characters of organisms "related to gathering resources, surviving in face of various threats, and reproducing" (Townsend and Hildrew 1994, p. 265). Their definition is similar to the one used by Violle et al. (2007) 13 y later. However, because of the difficulty of coding many species, the Rhône group described traits by 'modalities' (or categories), which were characterized by a 'fuzzy-coding' system (Chevenet et al. 1994) of partial-to-full membership of the species to the modality (Statzner et al. 1994, 1997, Charvet et al. 2000, Usseglio-Polatera et al. 2000). Fuzzy coding, which is based on reports from the literature on different trait affinities or on expert opinion, is done by assigning an integer score ranging from 0 (no affinity) to an arbitrary maximum, say 3 (high affinity), to express the affinity of a taxon to a par- 
ticular modality, such as the shredder feeding style. In several cases, fuzzy coded affinity scores (varying between 0 and 3) were expressed as percentages (varying between 0 and 100\%; Chevenet et al. 1994). The terminology proposed by the Rhône group is somewhat inconsistent with the proposed nomenclature of Violle et al. (2007) because for them (e.g., Statzner et al. 1994) the term 'trait' refers to a grouping feature (e.g., feeding style) and 'modality' to a variable (e.g., shredder trait).

After the work of the Rhône group, stream ecologists proposed additional, alternative nomenclatures for data tables related to traits. The resulting inconsistent use of common terms has made traits-based studies even more difficult to compare (Table 2). For example, in some cases, 'trait' refers to a grouping feature (e.g., numbers [nos] 1 and 2 in Table 2), whereas in other cases, it refers to a variable (e.g., nos 3, 4, 5, and 6). Furthermore, the term 'category' is variously used as a grouping feature, variable, and state (nos 2, 3, and 4). This multiple nomenclature related to traits may appear trivial and transparent at first sight, but it causes considerable difficulties in finding a consistent terminology for comparisons of results, metaanalyses, and reviews. The fact that the same term is used with different meanings hampers scientific communication even within the single field of stream ecology.
The need for clarification of terms is obvious in stream ecology, and without clarification, findings derived from stream studies cannot be integrated into other fields of ecology. The relationship between species traits and environmental factors is studied frequently in terrestrial plant communities (e.g., Lavorel and Garnier 2002), terrestrial animal assemblages (e.g., Jennings and Pocock 2009), and in efforts to link organismal, community, and ecosystem ecology (Webb et al. 2010). However, the results and findings are much more likely to be appropriately interpreted and transferable among studies if our trait nomenclature conforms to general statistical principles. For example, if a 'trait' represents a grouping feature (such as the range of different styles of acquiring food as in nos 1 and 2 in Table 2), then the relationship between the trait and environmental variables is not measurable or interpretable because the group of feeding styles itself does not vary with the environment. However, the specific feeding style of shredder will be expressed positively along a gradient of increasing coarse particulate organic matter (CPOM) in streams. Similarly, the relative frequency of the shredder trait in the whole community would be expected to increase along this CPOM gradient. In this case, the trait is a variable (Zar 1999) or descriptor (Legendre and Legendre 2012) as in no. 6 (Table 2) and the trait-environment relation is sensible. If the mem-

Table 3. Comparison of the original and the unified terminology.

\begin{tabular}{ll}
\hline \multicolumn{1}{c}{ Original proposal } & \multicolumn{1}{c}{ Unified terminology } \\
\hline Source: Usseglio-Polatera et al. (2000) & Grouping feature \\
Trait & Feeding style \\
Feeding habit & Trait \\
Modality & Absorber \\
Absorber & Deposit feeder \\
Deposit feeder & Shredder \\
Shredder & Scraper \\
Scraper & Filter-feeder \\
Filter-feeder & Piercer (including plants and animals) \\
Piercer (plants and animals) & Predator (including carver/engulfer/swallower) \\
Predator (carver/engulfer/swallower) & Parasite, parasitoid \\
Parasite, parasitoid & Membership state (ratio scale): from 0 to 100\% \\
Score (ratio scale): 0 or 1 or 2 or 3 & \\
Source: Poff et al. (2006) & Grouping feature \\
Trait & Feeding style \\
Trophic habit & Trait \\
State (Trait state/modality, nominal scale): & Collector-gatherer \\
Collector-gatherer & Collector-filterer \\
Collector-filterer & Herbivore (including scraper, piercer, and shredder) \\
Herbivore (scraper, piercer, and shredder) & Predator (including piercer and engulfer) \\
Predator (piercer and engulfer) & Shredder (including detritivore) \\
Shredder (detritivore) &
\end{tabular}


Table 4. The unified terminology applied to the biological traits of Usseglio-Polatera et al. (2000). Numbers follow UsseglioPolatera et al. (2000).

\begin{tabular}{|c|c|c|}
\hline No. & Grouping feature & Trait \\
\hline 1 & & Maximal size \\
\hline 2 & & Life-cycle duration \\
\hline 3 & & $\begin{array}{l}\text { Potential number of } \\
\text { reproduction cycles per year }\end{array}$ \\
\hline 4 & Aquatic stages & $\begin{array}{l}\text { Egg } \\
\text { Larva } \\
\text { Pupa } \\
\text { Adult }\end{array}$ \\
\hline 5 & Reproduction & $\begin{array}{l}\text { Ovovivipary } \\
\text { Isolated eggs, free } \\
\text { Isolated eggs, cemented } \\
\text { Clutches, cemented or fixed } \\
\text { Clutches, free } \\
\text { Eggs or clutches, in vegetation } \\
\quad \text { (endophytic) } \\
\text { Clutches, terrestrial } \\
\text { Asexual }\end{array}$ \\
\hline 6 & Dispersal medium & $\begin{array}{l}\text { Water } \\
\text { Air }\end{array}$ \\
\hline 6 & Dispersal mode & $\begin{array}{l}\text { Active } \\
\text { Passive }\end{array}$ \\
\hline 7 & Resistance form & $\begin{array}{l}\text { Eggs, statoblasts, gemmules } \\
\text { Cocoons } \\
\text { Cells against desiccation } \\
\text { Diapause or dormancy } \\
\text { None }\end{array}$ \\
\hline
\end{tabular}

bership of an individual or species in a trait can be scored as $0 / 1$ or $0-100 \%$ (nos 1 and 2), then referring to that membership as a discrete trait state (no. 6) is confusing. Below we propose a modified nomenclature that unifies the disparate terms and variable uses of terms in Table 2. First, however, we explore and define some finer details related to measurement scales in stream ecology.

\section{DIFFICULTIES IN HANDLING ORDINAL-SCALE DATA}

The treatment of ordinal-scale variables poses difficulties in statistical analysis in general (Pavoine et al. 2009) and in stream ecology in particular. For instance, Brooks et al. (2011) used traits of macroinvertebrate families with ordinal-scale states (sensu Poff et al. 2006), such as swimming ability and occurrence in drift, to characterize river communities. They coded these states by integer values (e.g., swimming ability: none [code $=1$ ], weak [2], and strong [3]) and then 'standardized' these values by division using the maximum value for the given trait (here 3). Last, they
Table 4 (Continued)

\begin{tabular}{|c|c|c|}
\hline No. & Grouping feature & Trait \\
\hline 8 & Respiration & $\begin{array}{l}\text { Tegument } \\
\text { Gill } \\
\text { Plastron } \\
\text { Spiracle (aerial) } \\
\text { Hydrostatic vesicle (aerial) }\end{array}$ \\
\hline 9 & $\begin{array}{l}\text { Locomotion and } \\
\text { substrate relation }\end{array}$ & $\begin{array}{l}\text { Flier } \\
\text { Surface swimmer } \\
\text { Crawler } \\
\text { Burrower (epibenthic) } \\
\text { Interstitial (endobenthic) } \\
\text { Temporary attached } \\
\text { Permanently attached }\end{array}$ \\
\hline 10 & Food & $\begin{array}{l}\text { Fine detritus }+ \text { microorganisms } \\
\text { Detritus }<1 \mathrm{~mm} \\
\text { Plant detritus } \geq 1 \mathrm{~mm} \\
\text { Living microphytes } \\
\text { Living macrophytes } \\
\text { Dead animal } \geq 1 \mathrm{~mm} \\
\text { Living microinvertebrates } \\
\text { Living macroinvertebrates }\end{array}$ \\
\hline 11 & Feeding style & $\begin{array}{l}\text { Absorber } \\
\text { Deposit feeder } \\
\text { Shredder } \\
\text { Scraper } \\
\text { Filter-feeder } \\
\text { Piercer (plants or animals) } \\
\text { Predator (carver/engulfer/swallower) } \\
\text { Parasite, parasitoid }\end{array}$ \\
\hline
\end{tabular}

calculated Euclidean distance to express similarity in traits among families. However, subtraction and division are not admissible for ordinal-scale data (Podani 2005, Engloner 2012; see also Table 1). For the same reason, the Euclidean distance measure is incompatible with ordinal-scale data (Podani 2000, Podani and Schmera 2006). The solutions to this problem are: 1$)$ the use of analytical methods developed for ordinal scale (Podani 2000, 2005), 2) the reduction of ordinal variables to nominal ones (as made by Poff et al. 2006), or 3) the expansion of the ordinal scale to an interval (or ratio) scale (as done in some analyses by Brooks et al. 2011). However, the expansion of the data scale should be justified and explained clearly to avoid mathematically nonsensical statements (i.e., standardization of an ordinal scale variable by its maximum). Furthermore, expansion requires additional information (here the difference between no and weak swimming ability is the same as the difference between weak and strong swimming ability), which is not free from arbitrariness. In sum, we suggest clear declaration of the data measurement scale(s) 
applied and the use of adequate analytical approaches. Moreover, ordinal-scale data cannot be analyzed with traditional statistical procedures (even if they are coded as 0,1 , and 2), because the difference (and the ratio) of such coded traits is not mathematically interpretable. As opposed to ordinal states, affinity scores (varying from 0 to some arbitrary maximum, say 3) used in fuzzy-coding systems are ratio-scale data. Thus, the affinity score 3 defines $3 \times$ higher affinity regarding the given trait than score 1 .

\section{A PROPOSAL}

Here, we propose a unified taxonomy of traits-related terms and a mathematically correct use of the term 'state'. First, we accept the definition of Violle et al. (2007) that a trait is a variable at the individual level (mathematically, a random variable) and reject the use of attribute (e.g., Violle et al. 2007) in the meaning of the state (in agreement with, e.g., Legendre and Legendre 2012). It follows that we should make some changes to the nomenclature of Statzner et al. (1994) because in their system 'trait' does not act as a variable. The terminology of Vieira et al. (2006) and Poff et al. (2006) fulfills the requirements of Violle et al. (2007), but it does not directly incorporate the use of the fuzzy-coding system (to characterize species with the affinity to different membership states), a system that is widely used in stream ecology (Statzner et al. 1994, Usseglio-Polatera et al. 2000, Lamouroux et al. 2002). Therefore, we suggest using the term grouping feature as a general property of related organismal traits, the term trait group for referring to related traits themselves, and the term trait, following Violle et al. (2007), as a morphological, physiological, or phenological feature measurable at the level of the individual organism (variable) that can be aggregated to the species level (Webb et al. 2010). Last, traits can be described by membership states on the nominal (yes/no) or ratio measurement scale (Table 3). This unified terminology produces changes in the terms of some coding systems (see nos 1, 2, and 4 in Table 2 for influenced terms and Table 3 for changes); it supplements some coding systems by the term group (see no. 6 in Table 2); and it requires some relabeling and recoding of the whole trait data table (see nos 3 and 5 in Table 2 for influenced terms and Table 3 for changes). To demonstrate these changes in a clear way, we applied our unified terminology to 2 trait tables frequently used in stream ecology (Tables 4, 5). Regarding the coding of Lamouroux et al. (2002), Vieira et al. (2006), and Poff et al. (2006), the changes include recoding nominal and ordinal-scale 'states' (e.g., shredder, predator, and other feeding styles) to the level of traits that have nominal codes with binary membership states $(0 / 1)$. Other existing nominal and ordinalscale traits in Poff et al. 2006 (or other tables) could be reorganized under the proposed system. For example, dispersal can be regarded as a grouping feature that includes several traits (e.g., female dispersal and adult flying strength;
Table 5. The unified terminology applied to the traits of Poff et al. (2006).

\begin{tabular}{|c|c|}
\hline Grouping feature & Trait \\
\hline Life history & $\begin{array}{l}\text { Number of generations per year } \\
\text { Development speed } \\
\text { Synchronization of emergence } \\
\text { Adult life span } \\
\text { Adult ability to exit } \\
\text { Ability to survive desiccation }\end{array}$ \\
\hline Dispersal & $\begin{array}{l}\text { Female dispersal } \\
\text { Adult flying strength }\end{array}$ \\
\hline Mobility & $\begin{array}{l}\text { Occurrence in drift } \\
\text { Maximum crawling rate } \\
\text { Swimming ability }\end{array}$ \\
\hline Morphology & $\begin{array}{l}\text { Degree of attachment } \\
\text { Degree of armoring }\end{array}$ \\
\hline Shape & Streamlining \\
\hline Respiration & $\begin{array}{l}\text { Tegument } \\
\text { Gills } \\
\text { Plastron, spiracle (aerial) } \\
\text { Size at maturity } \\
\text { Rheophily } \\
\text { Thermal preference }\end{array}$ \\
\hline Habit & $\begin{array}{l}\text { Burrow } \\
\text { Climb } \\
\text { Sprawl } \\
\text { Cling } \\
\text { Swim } \\
\text { Skate }\end{array}$ \\
\hline Feeding style & $\begin{array}{l}\text { Collector-gatherer } \\
\text { Collector-filterer } \\
\text { Herbivore (scraper, piercer, and shredder) } \\
\text { Predator (piercer and engulfer) } \\
\text { Shredder (detritivore) }\end{array}$ \\
\hline
\end{tabular}

Table 5) or can be characterized by different grouping features (Table 4), such as dispersal medium (using traits water and air) and dispersal mode (using traits active and passive) depending on the availability of ecological data. Similarly, life-history grouping feature might include traits number of generations per year, development speed, and others (Table 5).

Trait membership for individual traits could be coded as $0 / 1$ (as by Poff et al. 2006) or as $0-100 \%$ should fuzzycoding information be available. Some traits are interpretable within groups of traits, and the maximum value of a score can change among groups. Therefore, we recommend the use of percentages (i.e., 40\%) for affinity scores instead of raw scores (i.e., 3). By following these changes, one can avoid misunderstandings with the multiple mean- 
ings of the same terms. We recognize that many logical alternatives for organizing traits are possible. However, by following our proposed nomenclature, translations among approaches to trait organization would be straightforward, which would allow unambiguous interpretation and quantification of the relationship between traits and environmental variables.

Our suggestion also solves the problem of incorrect mathematical treatment of ordinal-scale data, because in the unified system, ordinal (and also nominal) data scales are transformed down to nominal-scale data with 2 states. No and yes are frequently coded as 0 and 1 in ecology (especially if they correspond to absence and presence, respectively).

\section{Conclusions}

Traits-based analyses provide a key tool to understanding variation in community structure in streams. However, the traits nomenclature used in stream ecology is inconsistent and ambiguous and, thus, difficult to translate to the broader ecological literature. Moreover, ordinalscale data-very commonly used in trait characterizations in stream ecology-are not always handled properly from a statistical perspective. Here, we have identified these shortcomings and proposed a unified terminology that allows better comparability among traits-based studies in stream ecology and research on other systems. We think that by identifying these shortcomings and provoking discussion on a more coherent terminology, we have helped the field of stream ecology proceed toward a unified terminology and an operative use of species traits.

\section{ACKNOWLEDGEMENTS}

We thank Sylvain Dolédec, Matthew Pyne, and Ryan McShane for their critical comments on the manuscript. The work of Tibor Erös was supported by the János Bolyai Research Scholarship. The research was supported by the Hungarian Scientific Research Grants OTKA K104279 and K106177 and by the Academy of Finland.

\section{LITERATURE CITED}

Anderberg, M. R. 1973. Cluster analysis for applications. Wiley, New York.

Bady, P., S. Dolédec, C. Fesl, S. Gayraud, M. Bacchi, and F. Schöll. 2005. Use of invertebrate traits for the biomonitoring of European large rivers: the effects of sampling effort on genus richness and functional diversity. Freshwater Biology 50:159-173.

Bêche, L. A., and V. H. Resh. 2007. Biological traits of benthic macroinvertebrates in California mediterranean-climate streams: long-term annual variability and trait diversity patterns. Fundamental and Applied Limnology 169:1-23.

Blanck, A., and N. Lamouroux. 2007. Large-scale intraspecific variation in life-history traits of European freshwater fish. Journal of Biogeography 34:862-875.

Brooks, A. J., B. C. Chessman, and T. Haeusler. 2011. Macroinvertebrate traits distinguish unregulated rivers subject to wa- ter abstraction. Journal of the North American Benthological Society 30:419-435.

Charvet, S., P. Usseglio-Polatera, and B. Dumont. 2000. Traits of benthic macroinvertebrates in semi-natural French streams: an initial application to biomonitoring in Europe. Freshwater Biology 43:277-296.

Chevenet, F., B. Statzner, S. Dolédec, and D. Chessel. 1994. A fuzzy coding approach for the analysis of long-term ecological data. Freshwater Biology 31:295-309.

Cummins, K. W. 1973. Trophic relations of aquatic insects. Annual Review of Entomology 18:183-206.

Dolédec, S., and S. Chessel. 1994. Co-inertia analysis: an alternative method for studying species-environment relationships. Freshwater Biology 31:277-294.

Dolédec, S., J. M. Olivier, and B. Statzner. 2000. Accurate description of the abundance of taxa and their biological traits in stream communities: effect of taxonomic and spatial resolution. Archiv für Hydrobiologie 148:25-43.

Dolédec, S., B. Statzner, and M. Bournaud. 1999. Species traits for future biomonitoring across ecoregions: patterns along a human-impacted river. Freshwater Biology 42:737-758.

Engloner, A. I. 2012. Alternative ways to use and evaluate Kohler's ordinal scale to assess aquatic macrophyte abundance. Ecological Indicators 20:238-243.

Gayraud, S., B. Statzner, P. Bady, A. Haybach, F. Schöll, P. Usseglio-Polatera, and M. Bacchi. 2003. Invertebrate traits for the biomonitoring of large European rivers: and initial assessment of alternative metrics. Freshwater Biology 48:20452064.

Haybach, A., F. Schöll, B. König, and F. Kohmann. 2004. Use of biological traits for interpreting functional relationships in large rivers. Limnologica 34:451-459.

Heino, J., D. Schmera, and T. Erős. 2013. A macroecological perspective of trait patterns in stream communities. Freshwater Biology 58:1539-1555.

Jennings, N., and M. J. O. Pocock. 2009. Relationships between sensitivity to agricultural intensification and ecological traits of insectivorous mammals and arthropods. Conservation Biology 23:1195-1203.

Lamouroux, N., N. L. Poff, and P. L. Angermeier. 2002. Intercontinental convergence of stream fish community traits along geomorphic and hydraulic gradients. Ecology 83:1792-1807.

Lavorel, S., and E. Garnier. 2002. Predicting changes in community composition and ecosystem functioning from plant traits: revisiting the Holy Grail. Functional Ecology 16:545556.

Lavorel, S., S. McIntyre, J. Landsberg, and T. D. A. Forbes. 1997. Plant functional classifications: from general groups to specific groups based on response to disturbance. Trends in Ecology and Evolution 12:474-478.

Legendre, P., and L. Legendre. 2012. Numerical ecology. $3^{\text {rd }}$ English edition. Elsevier, Amsterdam, The Netherlands.

McGill, B. J., B. J. Enquist, E. Weiher, and M. Westoby. 2006. Rebuilding community ecology from functional traits. Trends in Ecology and Evolution 21:178-185.

Pavoine, S., J. Vallet, A. B. Dufour, S. Gachet, and H. Daniel. 2009. On the challenge of treating various types of variables: application for improving the measurement of functional diversity. Oikos 118:391-402. 
Podani, J. 2000. Introduction to the exploration of multivariate biological data. Backhuys Publishers, Leiden, The Netherlands.

Podani, J. 2005. Multivariate exploratory analysis of ordinal data in ecology: pitfalls, problems and solutions. Iournal of Vegetation Science 15:497-510.

Podani, J., and D. Schmera. 2006. On dendrogram-based measures of functional diversity. Oikos 115:179-185.

Poff, N. L. 1997. Landscape filters and species traits: towards mechanistic understanding and prediction in stream ecology. Journal of the North American Benthological Society 16: 391-409.

Poff, N. L., J. D. Olden, N. K. M. Vieira, D. S. Finn, M. P. Simmons, and B. C. Kondratieff. 2006. Functional trait niches of North American lotic insects: traits-based ecological applications in light of phylogenetic relationships. Journal of the North American Benthological Society 25:730-755.

Poff, N. L., and J. V. Ward. 1990. Physical habitat template of lotic systems: recovery in the context of historical pattern of spatiotemporal heterogeneity. Environmental Management 14: 629-645.

Ricci, C. 1991. Comparison of five strains of parthenogenetic species, Macrotrachela quadricornifera (Rotifera, Bdelloidea). 1. Life-history traits. Hydrobiologia 211:147-155.

Schmera, D., J. Podani, and T. Erös. 2009. Measuring the contribution of community members to functional diversity. Oikos 118:961-971.

Schmera, D., J. Podani, T. Erős, and J. Heino. 2014. Combining taxon-by-trait and taxon-by-site matrices for analysing trait patterns of macroinvertebrate communities: a rejoinder to Monaghan \& Soares (2014). Freshwater Biology 59:15511557.

Sokal, R. R., and F. J. Rohlf. 1995. Biometry. W. H. Freeman and Company, New York.

Statzner, B., K. Hoppenhaus, M.-F. Arens, and P. Richoux. 1997. Reproductive traits, habitat use and templet theory: a synthesis of world-wide data on aquatic insects. Freshwater Biology 38:109-135.

Statzner, B., V. H. Resh, and S. Dolédec (editors). 1994. Ecology of the Upper Rhône River: a test of habitat templet theories. Freshwater Biology 31:253-554.

Townsend, C. R., and A. G. Hildrew. 1994. Species traits in relation to a habitat templet for river systems. Freshwater Biology 31:265-275.

Usseglio-Polatera, P., M. Bournaud, P. Richoux, and H. Tachet. 2000. Biological and ecological traits of benthic freshwater macroinvertebrates: relationships and definition of groups with similar traits. Freshwater Biology 43:175-205.

Vaughn, C. C., F. P. Gelwick, and W. J. Matthews. 1993. Effects of algivorous minnows on production of grazing stream invertebrates. Oikos 66:119-128.

Verberk, W. C. E. P., C. G. E. van Noordwijk, and A. G. Hildrew. 2013. Delivering on a promise: integrating species traits to transform descriptive community ecology into a predictive science. Freshwater Science 32:531-547.

Vieira, N. K. M., N. L. Poff, D. M. Carlisle, S. R. Moulton, M. L. Koski, and B. C. Kondratieff. 2006. A database of lotic invertebrate traits for North America. U.S. Geological Survey Data Series 187. US Geological Survey, US Department of the Interior, Reston, Virginia.

Violle, C., M. L. Navas, D. Vile, E. Kazakou, C. Fortunel, I. Hummel, and E. Garnier. 2007. Let the concept of trait be functional! Oikos 116:882-892.

Webb, C. T., J. A. Hoeting, G. M. Ames, M. I. Pyne, and N. L. LeRoy. 2010. A structured and dynamic framework to advance traits-based theory and prediction in ecology. Ecology Letters 13:267-283.

Winemiller, K. O. 1991. Ecomorphological diversification in lowland freshwater fish assemblages from five biotic regions. Ecological Monographs 61:343-365.

Zar, J. H. 1999. Biostatistical analyses. $4^{\text {th }}$ edition. Prentice Hall, Upper Saddle River, New Jersey. 